\title{
Incretin based treatments and mortality in patients with type 2 diabetes: systematic review and meta-analysis
}

\author{
Jiali Liu, ${ }^{1}$ Ling Li,, ${ }^{1}$ Ke Deng, ${ }^{1}$ Chang Xu, ${ }^{1}$ Jason W Busse,,3,4 Per Olav Vandvik, ,,6 Sheyu Li, ${ }^{7}$ \\ Gordon H Guyatt, 2,8 Xin Sun ${ }^{1}$
}

${ }^{1}$ Chinese Evidence-based Medicine Centre and CREAT

Group, State Key Laboratory of Biotherapy, West China

Hospital, Sichuan University and Collaborative Innovation Centre, Chengdu, 610041

Sichuan, China

2Department of Health Research Methods, Evidence and Impact, McMaster University, Hamilton,

ON L8S 4K1, Canada

${ }^{3}$ Department of Anesthesia, McMaster University, Hamilton, ON L8S 4K1, Canada

${ }^{4}$ Michael G DeGroote Institute for Pain Research and Care, McMaster University, Hamilton, ON L8S 4K1, Canada

${ }^{5}$ Norwegian Knowledge Centre for the Health Services, N-0130 Oslo, Norway

${ }^{6}$ Department of Medicine, Innlandet Hospital Trust, 2819 Gjøvik, Norway

7Department of Endocrinology and Metabolism, West China Hospital, Sichuan University,

Chengdu, 610041, Sichuan, China ${ }^{8}$ Department of Medicine, McMaster University, Hamilton, ON L8S 4K1, Canada

Correspondence to:

XSun sunx26@gmail.com

Additional material is published online only. To view please visit the journal online.

Cite this as: BMJ 2017;357:j2499 http://dx.doi.org/10.1136/bmj.j2499

Accepted: 11 May 2017

\author{
ABSTRACT \\ OBJECTIVE \\ To assess the impact of incretin based treatment on all \\ cause mortality in patients with type 2 diabetes. \\ DESIGN
}

Systematic review and meta-analysis of randomised trials. DATA SOURCES

Medline, Embase, the Cochrane Central Register of Controlled Trials (CENTRAL), and ClinicalTrials.gov.

\section{ELIGIBILITY CRITERIA}

Randomised controlled trials that compared glucagonlike peptide-1 (GLP-1) receptor agonists or dipeptidyl peptidase-4 (DPP-4) inhibitors with placebo or active anti-diabetic drugs in patients with type 2 diabetes.

\section{DATA COLLECTION AND ANALYSIS}

Paired reviewers independently screened citations, assessed risk of bias of included studies, and extracted data. Peto's method was used as the primary approach to pool effect estimates from trials, sensitivity analyses were carried out with other statistical approaches, and meta-regression was applied for six prespecified hypotheses to explore heterogeneity. The GRADE approach was used to rate the quality of evidence.

\section{RESULTS}

189 randomised controlled trials $(\mathrm{n}=155145)$ were included, all of which were at low to moderate risk of bias; 77 reported no events of death and 112 reported 3888 deaths among 151614 patients. Meta-analysis of 189 trials showed no difference in all cause mortality between incretin drugs versus control (1925/84136 V $1963 / 67478$; odds ratio $0.96,95 \%$ confidence interval 0.90 to $1.02, \mathrm{I}^{2}=0 \%$; risk difference 3 fewer events (95\% confidence interval 7 fewer to 1 more) per 1000 patients over five years; moderate quality evidence). Results suggested the possibility of a mortality benefit with GLP-1 agonists but not DPP-4 inhibitors, but the

\section{WHAT IS ALREADY KNOWN ON THIS TOPIC}

Concern has arisen as to whether incretin based treatments are associated with increased mortality, given a recent large randomised trial (SAVOR-TIMI 53 study) that suggested possible increased mortality with saxagliptin versus placebo Although previously meta-analyses have explored this question, they had important methodological limitations and did not consider much of the currently available evidence

\section{WHAT THIS STUDY ADDS}

The current evidence provides no support for the hypothesis that incretin based treatment increases all cause mortality in patients with type 2 diabetes

Further studies are warranted to examine if the effect differs between GLP-1 agonists and DPP-4 inhibitors

subgroup hypothesis had low credibility. Sensitivity analyses showed no important differences in the estimates of effects.

\section{CONCLUSIONS}

Current evidence does not support the suggestion that incretin based treatment increases all cause mortality in patients with type 2 diabetes. Further studies are warranted to examine if the effect differs between GLP-1 agonists versus DPP-4 inhibitors.

\section{Introduction}

Incretin based treatments, including dipeptidyl peptidase-4 (DPP-4) inhibitors and glucagon-like peptide-1 (GLP1) receptor agonists, represent important options for treating people with type 2 diabetes. ${ }^{1}$ The American Diabetes Association and the European Association for the Study of Diabetes (EASD) have recommended these drug classes as second line agents for treatment of type 2 diabetes. ${ }^{2}$ Their effects on glucose control are well established, ${ }^{3-5}$ with additional benefits of weight loss, antihypertensive effects, and minimal risk of hypoglycemia. ${ }^{4-11}$

A recent large randomised trial (SAVOR-TIMI 53 study $^{12}$ ) including patients with type 2 diabetes with established, or at risk for, cardiovascular disease, however, suggested possible increased mortality with saxagliptin versus placebo $(5.1 \% v 4.6 \%)$. In response, the US Food and Drug Administration released the following statement in 2015: "A potential increase in all cause mortality with saxagliptin was observed-The ITT on-study analysis suggested an increase in all-cause mortality (HR=1.11, 95.1\% CI [0.96 to 1.27]) based on about 800 observed deaths-Sensitivity analyses that censored subjects after treatment exposure showed more unfavorable trends in the risk of all cause mortality-Such trends were observed for both CV and non-CV related causes of death."13

This observation raised concern as to whether incretin based treatments could be associated with increased mortality; however, findings from other large trials were inconsistent. The TECOS ${ }^{14}$ and the EXAMINE trial $^{15}$-testing effects of sitagliptin and alogliptinfound no significant increase in mortality. Evidence from observational studies is also inconsistent. ${ }^{16-21}$ We therefore carried out a systematic review and meta-analysis of randomised controlled trials to determine the effect of incretin based treatments on mortality in patients with type 2 diabetes.

\section{Methods}

We followed the reporting standards for systematic reviews and meta-analyses of randomised controlled trials according to the PRISMA statements. ${ }^{22}$ 
Eligibility criteria

We included randomised controlled trials that compared GLP-1 agonists or DPP-4 inhibitors against placebo, lifestyle modification, or active anti-hyperglycaemic drugs in patients with type 2 diabetes. Eligible studies reported $\geq 12$ weeks' follow-up and explicitly reported data on all cause mortality.

\section{Literature search}

We searched Medline, Embase, and the Cochrane Central Register of Controlled Trials (CENTRAL) to identify relevant studies from inception to 18 February 2017, without language restrictions. We used database specific subject headings (such as $\mathrm{MeSH}$ terms) and free texts terms to search for potentially eligible studies (appendix 1). We searched ClinicalTrials.gov to identify additional relevant clinical trials and confirmed mortality data from all eligible published trials. This trial registry documents all phase II-IV drug trials as required by section 801 of the US Food and Drug Administration Amendments Act (FDAAA 801)23 and typically includes extensive lists of adverse events. ${ }^{24}$

\section{Study selection}

Paired reviewers, trained in research methods, independently and in duplicate screened titles/abstracts and full texts for eligible articles, assessed risk of bias, and extracted data from each eligible study using standardised pilot tested forms with detailed instructions. Reviewers dealt with discrepancies through discussion or, if necessary, arbitration by a third reviewer.

\section{Risk of bias assessment}

Two reviewers independently assessed risk of bias of randomised controlled trials using a modified Cochrane risk of bias instrument that includes response options of "definitely or probably yes" (assigned a low risk of bias) or "definitely or probably no" (assigned a high risk of bias), an approach we have previously validated. ${ }^{25-27}$ The items included random sequence generation; allocation concealment; blinding of participants, caregivers, outcome assessors and outcome adjudicators; infrequent missing outcome data; selective outcome reporting; and other sources of bias (details available at www.evidencepartners.com/resources/methodological-resources/).

\section{Data extraction}

For randomised controlled trials, we collected information regarding study characteristics (such as author name, year of publication, study design, sample size, length of follow-up), intervention characteristics (such as baseline treatment, type, dose, and duration of study treatment); patients' characteristics (such as age, sex, duration of type 2 diabetes, cardiovascular disease, body mass index (BMI), baseline $\mathrm{HbA}_{1 \mathrm{c}}$, fasting plasma glucose); and mortality outcomes (that is, number of deaths and patients included for analyses in each treatment group). If a published trial did not report the number of deaths, while the corresponding registry report from ClinicalTrials.gov reported mortality, we used outcome data from the registry report. In an extension phase of a trial, if the initial treatment assignment was switched, we collected the outcome data before that point. For trials with multiple follow-up points, data, or reports, we collected outcome data at the longest follow-up. ${ }^{28}$

\section{Data analysis and rating quality of evidence}

We conducted a meta-analysis of all included trials using the reported deaths from treatment and control groups. Given the low event rates in many trials, we used Peto's method as the primary analysis to pool effect estimates across studies. ${ }^{29}$ We excluded studies in which no deaths occurred in either study arm.

We conducted sensitivity analyses to examine the impact of using alternative effect measures (odds ratio versus relative risk), pooling methods (Peto versus Mantel-Hanszel (M-H)), statistical models (fixed versus random effects), continuity correction of 0.5 for trials with no events when pooling with the $\mathrm{M}-\mathrm{H}$ method (versus excluding such trials), ${ }^{3031}$ and analysis of trials with two or more events (that is, excluding trials with no events or only one event).

We generated a funnel plot and applied Egger's test to examine publication bias. We also conducted an additional test for publication bias by excluding trials with only one event.

We used the Cochran's $\chi^{2}$ test and the $\mathrm{I}^{2}$ statistic to examine statistical heterogeneity. Following recent guidance for a credible subgroup effect, ${ }^{32}$ we planned six hypotheses to explain variability in effect estimates of all cause mortality between studies: risk of cardiovascular disease at baseline (with low versus high versus unclear risk; larger effect in patients with low risk of cardiovascular comorbidities at baseline); type of incretin drug (DPP-4 inhibitors versus GLP-1 agonists; larger effect in trials testing GLP-1 agonists); length of follow-up ( 52 weeks or shorter versus over 52 weeks; larger effect in trials with longer follow-up); type of control (placebo versus active treatment; larger effect in trials with placebo control); mode of treatment (monotherapy versus add on/combination; larger effect in trials with add on/combination treatment); and individual incretin drugs (different incretins). We conducted univariable random effects meta-regression for each of the six hypotheses, when there were at least 10 trials available for analysis. We also conducted a post hoc multiple regression analysis adjusting for risk of cardiovascular disease at baseline, type of incretin drug, length of follow-up, type of control, and mode of treatment. To explore consistency of an apparent subgroup effect, we additionally conducted two univariable exploratory subgroup analyses by type of incretin drug, one on all cause mortality and another on cardiovascular events, using data from the six large cardiovascular outcome trials that compared either GLP-1 agonists or DPP-4 inhibitors versus placebo.

We used the GRADE approach to rate the quality of evidence and generate absolute estimates of effect for the outcomes. ${ }^{33}$ To calculate the absolute increase in risk for mortality, we estimated the baseline risk for death from a large cohort study ${ }^{16}$ that enrolled patients without previous myocardial infarction or stroke. 


\section{Patient involvement}

No patients were involved in setting the research question or the outcome measures, nor were they involved in developing plans for design or implementation of the study. No patients were asked to advise on interpretation or writing up of results. There are no plans to disseminate the results of the research to study participants or the relevant patient community.

\section{Results}

Of 19250 unique reports, reviewers judged 1187 as potentially eligible at title and abstract screening; of these, 189 randomised controlled trials involving 155145 participants proved eligible (fig 1).

\section{Study characteristics}

All 189 randomised controlled trials were funded by industry. Among those, 126 enrolled patients with type 2 diabetes at low risk of cardiovascular disease at baseline (specifically excluding patients with certain cardiovascular diseases), and 55 enrolled patients with unclear risk of cardiovascular disease at baseline (without mention of excluding patients with cardiovascular disease). The eight others enrolled patients at high risk of, or with established, cardiovascular disease at baseline, including six large cardiovascular outcomes trials (tables A and B in appendix 2).

The six large cardiovascular outcome trials (TECOS, 14 LEADER, ${ }^{34}$ SUSTAIN-6, ${ }^{35}$ ELIXA, ${ }^{36}$ SAVOR-TIMI 53,12 and EXAMINE ${ }^{15}$ trial) enrolled 3297 to 16492 patients at high risk of, or with established, cardiovascular disease at baseline, followed patients for a median of 1.5 to 3.8 years, and evaluated one of six incretin agents (sitagliptin, liraglutide, semaglutide, lixisenatide, saxagliptin, or alogliptin) versus placebo. The trials enrolled similar patients: mean age range 60.3-65.0, mean BMI 29.5-32.8, mean baseline $\mathrm{HbA}_{1 \mathrm{c}}$ 7.2-8.7\%, mean fasting plasma glucose $8.2-8.7 \mathrm{mmol} / \mathrm{L}$, and a mean or median duration of diabetes of 7.2-13.9 years (table A in appendix 2).

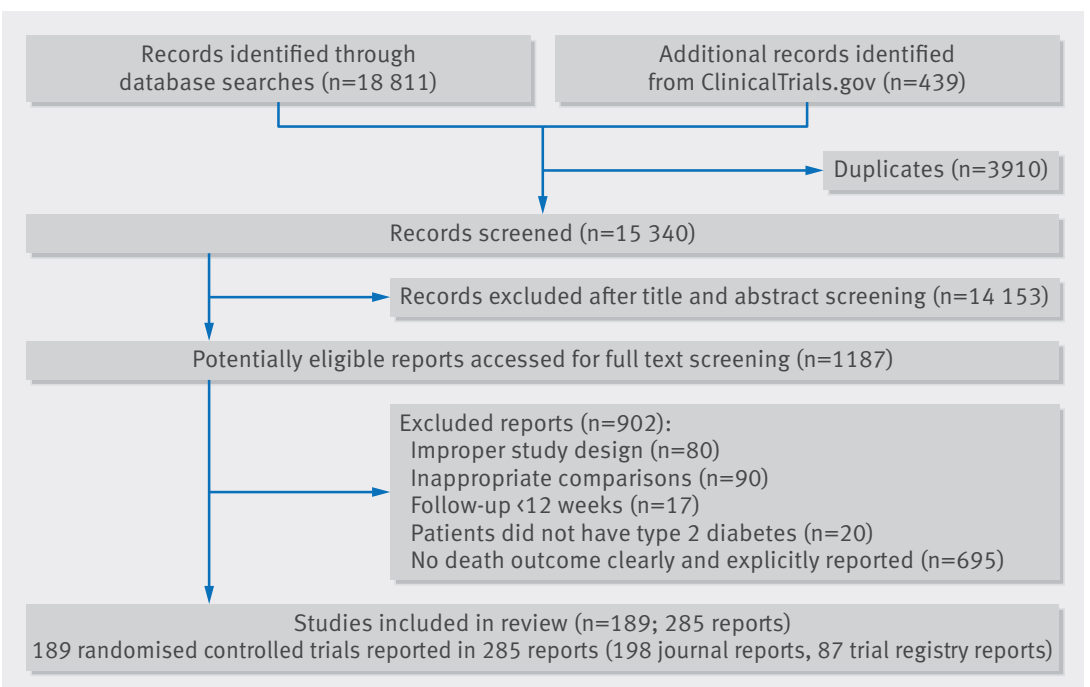

Fig 1 | Flow chart of selection of studies on incretin based treatments and mortality in patients with type 2 diabetes
Of the 183 other trials, 153 (83.6\%) were clearly labelled as phase III studies. The length of follow-up was 12-234 weeks (median 24 weeks; interquartile range 24-52 weeks); the mean age of participants range was 49.7-74.9; mean or median BMI 21.7-37.1; mean baseline $\mathrm{HbA}_{1 \mathrm{c}} 6.6 \%-10.2 \%$; mean fasting plasma glucose 6.2-12.2 $\mathrm{mmol} / \mathrm{L}$; and mean or median duration of diabetes 1.015.9 years (table A in appendix 2); 119 tested DPP-4 inhibitors, 68 GLP-1 agonists, and four tested both agents; 130 tested incretin drug versus placebo, 69 versus active comparator, 16 versus both placebo and active comparator; 71 used incretin drugs as monotherapy, 121 as add on/combination treatment, and nine administered both treatment options (table $\mathrm{C}$ in appendix 2).

\section{Risk of bias assessment}

Among the six large cardiovascular outcome trials, all adequately generated their randomisation sequence, concealed allocation, blinded patients and caregivers, and were free from reporting bias. Five (83.3\%) trials had infrequent missing outcome data. The baseline characteristics were generally similar between treatment groups across all the trials (table D in appendix 2).

Of the 183 other randomised controlled trials, 177 (96.7\%) adequately generated their randomisation sequence, 170 (92.9\%) concealed allocation, and 155 $(84.7 \%)$ blinded patients and caregivers. The baseline characteristics were generally similar between treatment groups in each trial. Only 47 (25.7\%), however, were free from frequent missing outcome data (table D in appendix 2).

\section{Effects on all cause mortality}

Of the 189 trials, 77 (40.7\%) reported that no deaths occurred during the course of study. The 112 other trials (59.3\%) reported 3888 deaths among 151614 patients, of which 3592 (92.4\%) were reported from the six large cardiovascular outcome trials.

Our meta-analysis including the 112 trials that reported at least one death showed no difference in mortality between incretin drug versus control (1925/84136 v 1963/67 478; odds ratio 0.96, 95\% confidence interval 0.90 to $1.02, \mathrm{I}^{2}=0 \%$; risk difference 3 fewer events (95\% confidence interval 7 fewer to 1 more) per 1000 patients over five years; moderate quality evidence, rated down because of inconsistency between GLP-1 agonists and DPP-4 inhibitors) (fig 2 and table 1). Trials that compared incretin treatment against placebo or no treatment contributed $97 \%$ of the weight to the analysis, and trials with an active comparator $4 \%$.

Our funnel plot and statistical test showed no evidence of publication bias (fig 3, Egger's test $\mathrm{P}=0.21$ ). Our analysis excluding trials with no events or one event across arms found a similar result (fig $A$ in appendix 3, Egger's test $P=0.33)$. Sensitivity analyses using an alternative effect measure (M-H relative risk 0.95, 95\% confidence interval 0.90 to 1.01), pooling method (M-H odds ratio $0.95,0.89$ to 1.01 ), statistical model (random effects M-H odds ratio $0.95,0.89$ to 1.02 ), continuity correction of 0.5 for trials with no events (M-H odds ratio $0.95,0.89$ to 1.01 ), and by excluding trials with no events 


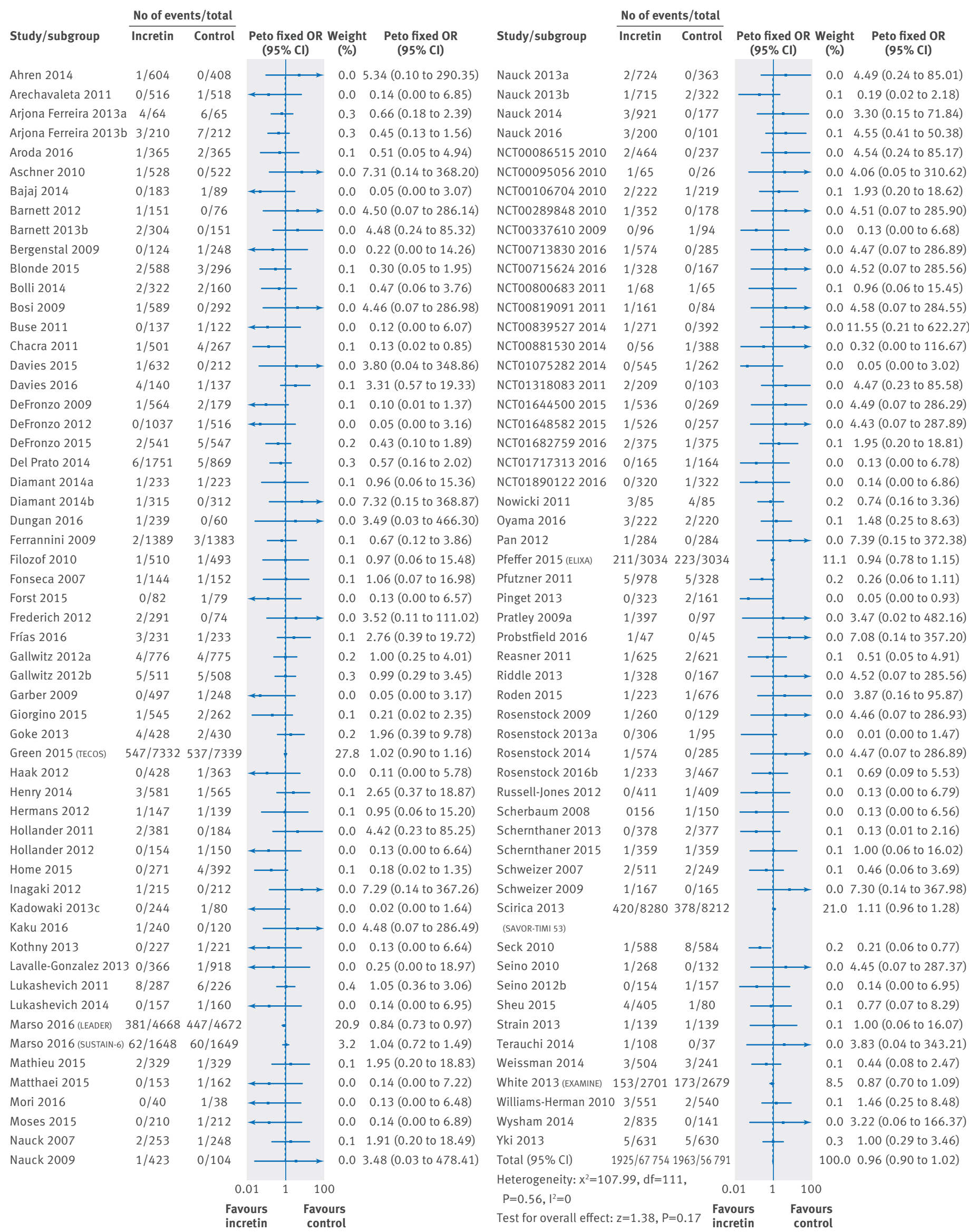

Fig 2 | All cause mortality in patients with type 2 diabetes receiving incretin based treatment versus control in randomised controlled trials 


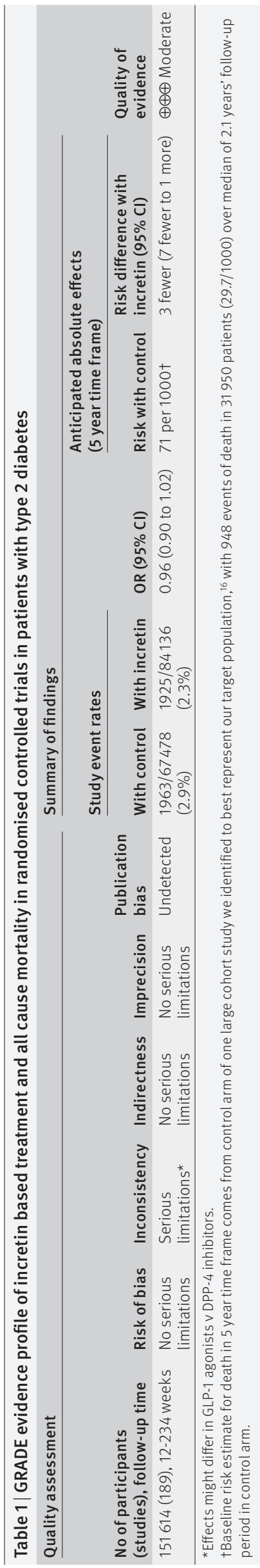

or one event across arms (Peto odds ratio 0.96, 0.90 to 1.02) showed similar results (table 2).

Univariable meta-regression showed no association between all cause mortality and any of our six subgroup factors $(\mathrm{P}=0.38$ for length of follow-up; $\mathrm{P}=0.20$ for risk of cardiovascular disease at baseline; $\mathrm{P}=0.52$ for type of incretin drug; $\mathrm{P}=0.05$ for type of control; $\mathrm{P}=0.80$ for mode of treatment; $\mathrm{P}=0.86$ for individual incretin agents; table 3). Subgroup analyses by type of incretin drug (GLP-1 agonists or DPP-4 inhibitors), with data from six large randomised trials that compared incretin agents versus placebo, showed similar finding for all cause mortality (interaction test $\mathrm{P}=0.09$; GLP-1 agonists versus placebo: 654/9350 v 730/9355; M-H odds ratio 0.89, 95\% confidence interval 0.80 to 0.99 ; DPP-4 inhibitors versus placebo: 1120/18313 v 1088/18230; 1.02, 0.91 to 1.14; fig 4) and composite cardiovascular events (interaction test $\mathrm{P}=0.19$; GLP-1 agonists versus placebo: $1113 / 9350 v$ 1229/9355; 0.88, 0.74 to 1.04; DPP-4 inhibitors versus placebo: 1527/18313 v 1527/18230; 0.99, 0.92 to 1.07; fig 5).

Multiple meta-regression, adjusted for length of follow-up, risk of cardiovascular disease at baseline, type of control, and mode of treatment, suggested that GLP-1 agonists, but not DPP-4 inhibitors, are associated with lower all cause mortality ( $\mathrm{P}=0.01$ for interaction).

\section{Discussion}

\section{Findings and interpretations}

Our systematic review and meta-analysis provides no support for the hypothesis that incretin based treatment is associated with increased mortality in patients with type 2 diabetes. This finding should reassure patients and clinicians and refutes the concern raised by the SAVOR-TIMI trial suggesting increased mortality.

In our univariable meta-regression, we found no differential effects among the six prespecified hypotheses; however, multiple meta-regression suggested that GLP-1 agonists, but not DPP-4 inhibitors, could be associated with lower mortality. When checked against 11 criteria $^{32}$ for assessing the credibility of an apparent subgroup effect, the following supports the hypothesis. The subgroup analysis was one of the small number of prespecified hypotheses tested; the characteristics were measured at baseline; the test for interaction, based on multiple meta-regression, was significant and the

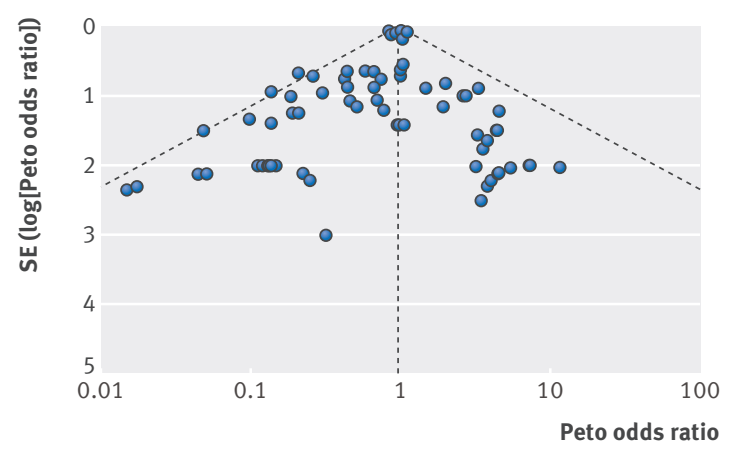

Fig 3 Funnel plot of mortality in patients with type 2 diabetes receiving incretin based treatment versus control in randomised controlled trials 


\begin{tabular}{|c|c|}
\hline Comparison & Point estimate $(95 \% \mathrm{Cl})$ \\
\hline Primary analysis & Peto OR 0.96 (0.90 to 1.02) \\
\hline \multicolumn{2}{|l|}{ Sensitivity analyses } \\
\hline Alternative effect measure: RR (fixed model) & RR 0.95 (0.90 to 1.01) \\
\hline GLP-1 agonists $v$ control & RR 0.89 (0.81 to 0.98$)$ \\
\hline DPP-4 inhibitors $v$ control & RR 0.99 (0.92 to 1.07) \\
\hline Alternative pooling method: Mantel-Hanszel's method (fixed model) & OR 0.95 (0.89 to 1.01$)$ \\
\hline GLP-1 agonists $v$ control & OR 0.89 (0.80 to 0.98$)$ \\
\hline DPP-4 inhibitors $v$ control & OR 0.99 (0.92 to 1.08$)$ \\
\hline Statistical models: random effects & OR 0.95 (0.89 to 1.02$)$ \\
\hline GLP-1 agonists $v$ control & OR 0.88 (0.80 to 0.98$)$ \\
\hline DPP-4 inhibitors $v$ control & OR 1.00 (0.92 to 1.08$)$ \\
\hline A continuity correction of 0.5 & OR 0.95 (0.89 to 1.01$)$ \\
\hline Excluding trials with zero or one event across arms & Peto OR 0.96 (0.90 to 1.02) \\
\hline
\end{tabular}

additional exploratory subgroup analysis of a subset of the six large cardiovascular outcome trials showed a similar trend; the subgroup findings seemed to be consistent across related outcomes (such as cardiovascular events, fig 5); and, in terms of biological rationale, animal studies and randomised controlled trials in humans have shown that GLP-1 agonists are associated with a larger sustainable reduction of $\mathrm{HbA}_{1 \mathrm{c}},{ }^{37}$ weight loss, and systolic blood pressure control than DPP-4 inhibitors. ${ }^{38} 39$

On the other hand, the subgroup analysis is based on a comparison between trials; it is not robust across statistical analyses (the effect did not appear in the univariable analysis but only in the meta-regression, and the meta-regression is at high risk of over-fitting-six trials account for $92.5 \%$ of the weight), and was not prespecified; the apparent reduction in mortality with GLP-1 is both small and of borderline significance. We thus conclude that the subgroup hypothesis has low credibility.

\section{Strengths and limitations}

Strengths of our review include a systematic and rigorous approach to the identification of randomised controlled trials investigating the impact of incretin based treatment on mortality. We conducted a limited number of preplanned subgroup analyses to explore for differences in risk of mortality. We used the GRADE approach to assess the quality of evidence that showed

\begin{tabular}{|c|c|c|c|}
\hline \multirow[b]{2}{*}{ Comparison } & \multirow[b]{2}{*}{$\begin{array}{l}\text { Peto odds ratio } \\
(95 \% \mathrm{Cl})\end{array}$} & \multicolumn{2}{|l|}{$P$ value } \\
\hline & & $\begin{array}{l}\text { Univariable } \\
\text { meta-regression }\end{array}$ & $\begin{array}{l}\text { Multiple } \\
\text { meta-regression }\end{array}$ \\
\hline \multicolumn{4}{|c|}{ Subgroup by patients cardiovascular disease risk at baseline: } \\
\hline Low baseline risk & 0.77 (0.58 to 1.03$)$ & \multirow{3}{*}{0.20} & \multirow{3}{*}{0.58} \\
\hline High baseline risk or established CVD & $0.97(0.91$ to 1.04$)$ & & \\
\hline Unclear risk & 0.75 (0.49 to 1.15$)$ & & \\
\hline \multicolumn{4}{|l|}{ Subgroup by type of incretin drugs*: } \\
\hline GLP-1 agonists $v$ control & $0.89(0.80$ to 0.99$)$ & \multirow{2}{*}{0.52} & \multirow{2}{*}{0.01} \\
\hline DPP-4 inhibitors $v$ control & $1.00(0.92$ to 1.08$)$ & & \\
\hline \multicolumn{4}{|l|}{ Subgroup by type of control: } \\
\hline Incretin drugs $v$ placebo & 0.94 (0.89 to 1.01$)$ & \multirow{2}{*}{0.05} & \multirow{2}{*}{0.44} \\
\hline Incretin drugs $v$ active drugs & 0.65 (0.47 to 0.91$)$ & & \\
\hline \multicolumn{4}{|l|}{ Subgroup by length of follow-up: } \\
\hline$\leq 52$ weeks & 0.81 (0.59 to 1.12$)$ & \multirow{2}{*}{0.38} & \multirow{2}{*}{0.52} \\
\hline$>52$ weeks & 0.96 (0.90 to 1.03$)$ & & \\
\hline \multicolumn{4}{|l|}{ Subgroup by mode of treatment: } \\
\hline Monotherapy & 0.88 (0.59 to 1.31$)$ & \multirow{2}{*}{0.80} & \multirow{2}{*}{0.80} \\
\hline Add-on/combination treatment & 0.96 (0.89 to 1.02$)$ & & \\
\hline \multicolumn{4}{|l|}{ Subgroup by individual agents: } \\
\hline Alogliptin & $0.86(0.69$ to 1.07$)$ & \multirow{14}{*}{0.86} & \multirow{14}{*}{ NAt } \\
\hline Linagliptin & $0.72(0.36$ to 1.45$)$ & & \\
\hline Omarigliptin & 0.90 (0.20 to 4.08$)$ & & \\
\hline Saxagliptin & $1.07(0.94$ to 1.23$)$ & & \\
\hline Sitagliptin & 1.00 (0.89 to 1.13$)$ & & \\
\hline Teneligliptin & $0.02(0.00$ to 1.64$)$ & & \\
\hline Vildagliptin & $0.72(0.38$ to 1.37$)$ & & \\
\hline Albiglutide & 0.86 (0.30 to 2.48$)$ & & \\
\hline Dulaglutide & $0.68(0.23$ to 2.00$)$ & & \\
\hline Exenatide & $1.32(0.60$ to 2.90$)$ & & \\
\hline Liraglutide & 0.85 (0.74 to 0.98$)$ & & \\
\hline Lixisenatide & 0.93 (0.76 to 1.12$)$ & & \\
\hline Semaglutide & 1.04 (0.72 to 1.49$)$ & & \\
\hline Taspoglutide & $0.17(0.02$ to 1.36$)$ & & \\
\hline
\end{tabular}


Fig 4 All cause mortality in patients with type 2 diabetes receiving incretin based treatment versus placebo in large cardiovascular outcomes trials
Study/subgroup

GLP-1 agonists

Marso 2016 (LEADER)

Marso 2016 (SUSTAIN-6)

Pfeffer 2015 (ELIXA)

Subtotal

Test for heterogeneity: $\tau^{2}=0.00, \chi^{2}=1.62, \mathrm{df}=2, \mathrm{P}=0.44, \mathrm{I}^{2}=0 \%$

Test for overall effect: $z=2.11, P=0.03$

DPP-4 inhibitors

Green 2015 (TECOS)

Scirica 2013 (SAVOR-TIMI 53)

White 2013 (EXAMINE)

Subtotal

Test for heterogeneity: $\tau^{2}=0.00, \chi^{2}=3.19, \mathrm{df}=2, \mathrm{P}=0.20, \mathrm{I}^{2}=37 \%$

Test for overall effect: $z=0.03, P=0.74$

Total $(95 \% \mathrm{Cl})$

$1774 / 27663 \quad 1818 / 27585$

Test for heterogeneity: $\tau^{2}=0.01, \chi^{2}=8.98, d f=5, P=0.11, I^{2}=44 \%$

Test for overall effect: $z=0.70, P=0.48$

Test for subgroup differences: $\chi^{2}=2.92, \mathrm{df}=1, P=0.09, \mathrm{I}^{2}=66 \%$

$381 / 4668 \quad 447 / 4672$

$62 / 1648 \quad 60 / 1649$

$211 / 3034 \quad 223 / 3034$

$654 / 9350 \quad 730 / 9355$

$47 / 733$

$420 / 8280 \quad 378 / 8212$

$153 / 2701 \quad 173 / 2679$

$1120 / 18313 \quad 1088 / 18230$
Incretin Control

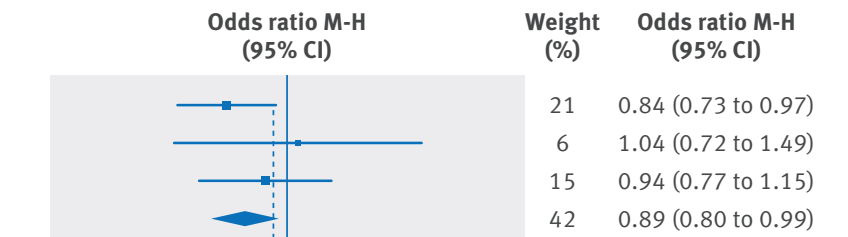

ds ratio $\mathrm{M}-\mathrm{H}$

(1)

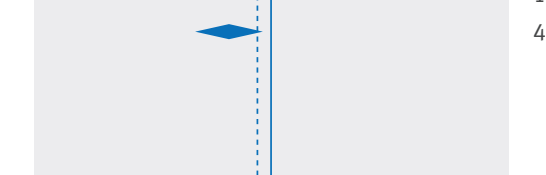

$24 \quad 1.02$ (0.90 to 1.16$)$

$21 \quad 1.11$ (0.96 to 1.28$)$

$13 \quad 0.87$ (0.69 to 1.09$)$

$58 \quad 1.02(0.91$ to 1.14$)$

$100 \quad 0.97$ (0.88 to 1.06$)$

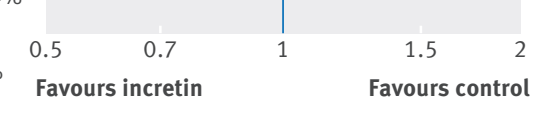

convincing evidence that incretin drugs do not increase mortality (table 1).

Our study also has limitations. Firstly, studies might selectively report data regarding death in their full publications, which could lead to risk of selection bias; we attempted to mitigate this risk by reviewing records on ClinicalTrials.gov for unreported deaths and included outcome data from 23 trial registry reports. Secondly, we were unable to assess the long term effects of these drugs: among the 189 trials, only 40 had long term follow-up over 52 weeks, and the longest follow-up in the large trials was 3.8 years. Our subgroup analysis suggesting a possible reduction in mortality with GLP-1 agonists but not with DPP4 inhibitors has limited credibility. We identified 11 trials reporting head-to-head comparison, ${ }^{40-50}$ but with limited information-15 events from 6736 participantsand thus estimates were uninformative.

\section{Comparison with other studies}

Three previous meta-analyses ${ }^{51-53}$ have reported the effect of GLP-1 agonists, versus placebo or active treatments, on all cause mortality among patients with type 2 diabetes. One, including 33 trials with more than 12 weeks' follow-up, nine of which reported at least one death, showed that GLP-1 receptor agonists did not seem to be associated with increased mortality (odds ratio $0.67,95 \%$ confidence interval 0.26 to 1.78$)^{51}$; another one, including 33 trials with more than 24 weeks' follow-up, 14 of which reported at least one death, found similar results $(0.89,0.46$ to 1.70$) .{ }^{52}$ The other recently published meta-analysis, including five trials with the outcome of mortality, found no effect of GLP-1 agonists on mortality (relative risk 0.90 , 95\% confidence interval 0.70 to 1.15$). .^{53}$ In comparison, our results, primarily based on large cardiovascular
Fig 5 | Composite cardiovascular events (death from cardiovascular causes, non-fatal myocardial infarction, or non-fatal stroke) in patients with type 2 diabetes receiving incretin based treatment versus placebo in large cardiovascular outcomes trials

\begin{tabular}{lc}
\multicolumn{2}{c}{ No of events/total } \\
\hline Incretin & Control \\
& \\
$608 / 4668$ & $694 / 4672$ \\
$108 / 1648$ & $146 / 1649$ \\
$397 / 3034$ & $389 / 3034$ \\
$1113 / 9350$ & $1229 / 935$
\end{tabular}

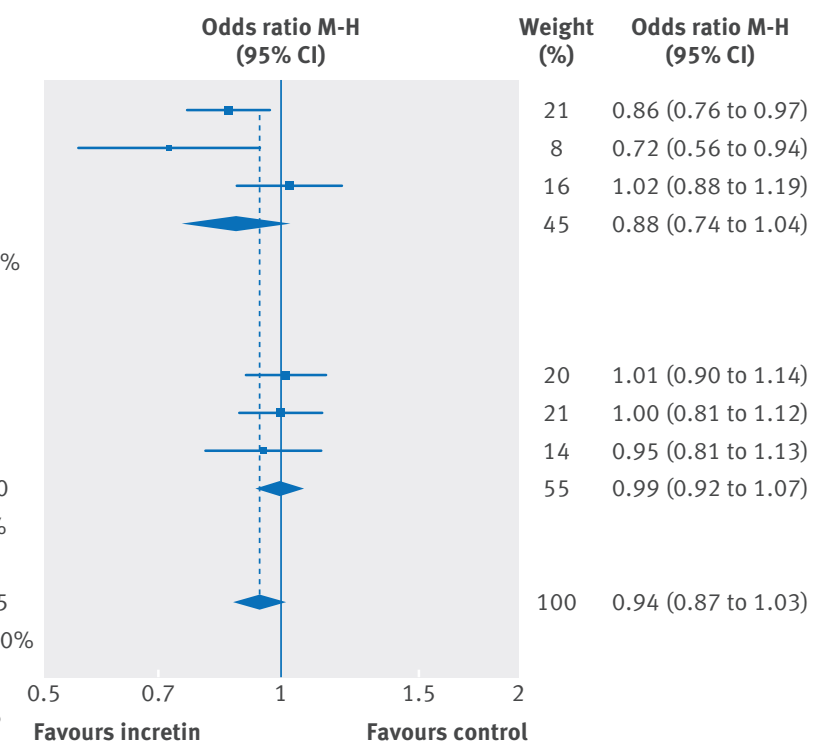


outcome trials, suggest that GLP-1 agonists could be associated with lower mortality in patients at high risk of, or with, established cardiovascular disease.

Four previous meta-analyses have reported the effect of DPP-4 inhibitors, versus placebo or active treatments, on all cause mortality among patients with type 2 diabetes. ${ }^{54-57}$ Monami and colleagues, who included 41 trials with more than 12 weeks' follow-up, 18 of which reported at least one death, suggested that DPP-4 inhibitors did not increase mortality (odds ratio 0.78, 95\% confidence interval 0.40 to 1.51$).{ }^{54}$ Savarese and colleagues found no effect of DPP-4 inhibitors on mortality regardless of length of follow-up (relative risk 1.06, 95\% confidence interval 0.56 to 2.01, for follow-up $<29$ weeks; $1.01,0.91$ to 1.13 , for follow-up $\geq 29$ weeks). ${ }^{55} \mathrm{Wu}$ and colleagues, who included 43 randomised controlled trials with 50982 patients and 1228 deaths, found similar results (1.01, 0.91 to 1.13$).{ }^{56}$ The final study, also by Savarese and colleagues, included 66 trials with sample size more than 200 patients and report of at least one death, and again found no effect on mortality (odds ratio 1.01, 95\% confidence interval 0.93 to 1.09 ). ${ }^{57}$ Our study, including 122 smaller trials and three larger trials, showed, with much narrower confidence intervals, that DPP-4 inhibitors had minimal or no impact on mortality.

Compared with these studies, we included a large number of additional studies (38 additional randomised controlled trials of GLP-1 agonists and 56 of DPP-4 inhibitors) and conducted more thorough analyses. The addition of large cardiovascular outcome trials provided more reliable estimates of effects on mortality, and subgroup analysis raised the possibility of differential effects of the two classes of incretin drugs-though the subgroup hypothesis has low credibility. ${ }^{32}$

\section{Conclusions}

Our results provide no support for the hypothesis that incretin based treatment are associated with increased all cause mortality in patients with type 2 diabetes. Additional large well designed randomised trials with adequate follow-up will be necessary to definitively establish or refute possible differences in the effect of GLP-1 agonists and DPP-4 inhibitors on all cause mortality.

We thank Daphne Plaut for developing the search strategy and conducting the initial literature search.

Contributors: JL, LL, and KD contributed equally to this work. XS, LL, and POV conceived the study. XS acquired the funding. XS, JL, LL, and KD had full access to all of the data in the study, and take responsibility for the integrity of the data and the accuracy of the data analysis. JL, LL, KD and CX conducted the literature searches and extracted the data. All authors conducted the analysis and interpreted the data and critically revised the manuscript. JL, LL and KD drafted the manuscript. XS is guarantor.

Funding: This study was supported by National Natural Science Foundation of China (grant No 71573183), "Thousand Youth Talents Plan" of China (grant No D1024002), and Sichuan Province, and Young Investigator Award of Sichuan University (grant No 2013SCU04A37). These funders had no role in the study design, writing of the manuscript, or decision to submit this or future manuscripts for publication. JWB is funded by a New Investigator Award from the Canadian Institutes of Health Research and Canadian Chiropractic Research Foundation. SL is funded by the National Natural Science Foundation of China (grant No 81400811 and 21534008).

Competing interests: All authors have completed the ICMJE uniform disclosure form at www.icmje.org/coi_disclosure.pdf and declare: no support from any organisation for the submitted work; no financial relationships with any organisations that might have an interest in the submitted work in the previous three years, and no other relationships or activities that could appear to have influenced the submitted work. Ethical approval: Not required.

Data sharing: No additional data available.

Transparency: The lead author (the manuscript's guarantor) affirms that the manuscript is an honest, accurate, and transparent account of the study being reported; that no important aspects of the study have been omitted; and that any discrepancies from the study as planned have been explained.

This is an Open Access article distributed in accordance with the Creative Commons Attribution Non Commercial (CC BY-NC 4.0) license, which permits others to distribute, remix, adapt, build upon this work non-commercially, and license their derivative works on different terms, provided the original work is properly cited and the use is noncommercial. See: http://creativecommons.org/licenses/by-nc/4.0/.

Nauck M. Incretin therapies: highlighting common features and differences in the modes of action of glucagon-like peptide-1 receptor agonists and dipeptidyl peptidase- 4 inhibitors. Diabetes Obes Metab 2016;18:203-16. doi:10.1111/dom.12591.

2 Inzucchi SE, Bergenstal RM, Buse JB, et al. Management of hyperglycemia in type 2 diabetes, 2015: a patient-centered approach: update to a position statement of the American Diabetes Association and the European Association for the Study of Diabetes. Diabetes Care 2015;38:140-9. doi:10.2337/dc14-2441.

3 Tricco AC, Antony J, Khan PA, et al. Safety and effectiveness of dipeptidyl peptidase- 4 inhibitors versus intermediate-acting insulin or placebo for patients with type 2 diabetes failing two oral antihyperglycaemic agents: a systematic review and network meta-analysis. BMJ Open 2014:4:e005752. doi:10.1136/bmjopen-2014-005752.

4 Karagiannis T, Paschos P, Paletas K, Matthews DR, Tsapas A. Dipeptidyl peptidase- 4 inhibitors for treatment of type 2 diabetes mellitus in the clinical setting: systematic review and meta-analysis. BMJ 2012;344:e1369. doi:10.1136/bmj.e1369.

5 Aroda VR, Henry RR, Han J, et al. Efficacy of GLP-1 receptor agonists and DPP-4 inhibitors: meta-analysis and systematic review. Clin Ther 2012;34:1247-1258.e22. doi:10.1016/i.clinthera.2012.04.013.

6 Zhang X, Zhao Q. Effects of dipeptidyl peptidase-4 inhibitors on blood pressure in patients with type 2 diabetes: A systematic review and meta-analysis. J Hypertens 2016;34:167-75. doi:10.1097/ HJH.0000000000000782.

7 Karagiannis T, Liakos A, Bekiari E, et al. Efficacy and safety of once-weekly glucagon-like peptide 1 receptor agonists for the management of type 2 diabetes: a systematic review and meta-analysis of randomized controlled trials. Diabetes Obes Metab 2015;17:1065-74. doi:10.1111/dom.12541.

8 Sun F, Chai S, Li L, et al. Effects of glucagon-like peptide-1 receptor agonists on weight loss in patients with type 2 diabetes: a systematic review and network meta-analysis. J Diabetes Res 2015;2015:157201. doi:10.1155/2015/157201.

9 Esposito K, Mosca C, Brancario C, Chiodini P, Ceriello A, Giugliano D. GLP-1 receptor agonists and HBA1C target of $<7 \%$ in type 2 diabetes: meta-analysis of randomized controlled trials. Curr Med Res Opin 2011:27:1519-28. doi:10.1185/03007995.2011.590127.

10 Katout M, Zhu H, Rutsky J, et al. Effect of GLP-1 mimetics on blood pressure and relationship to weight loss and glycemia lowering: results of a systematic meta-analysis and meta-regression. Am J Hypertens 2014;27:130-9. doi:10.1093/ajh/hpt196.

11 Kawalec P, Mikrut A, topuch S. The safety of dipeptidyl peptidase-4 (DPP-4) inhibitors or sodium-glucose cotransporter 2 (SGLT-2) inhibitors added to metformin background therapy in patients with type 2 diabetes mellitus: a systematic review and meta-analysis. Diabetes Metab Res Rev 2014;30:269-83. doi:10.1002/dmrr.2494.

12 Scirica BM, Bhatt DL, Braunwald E, et al. SAVOR-TIMI 53 Steering Committee and Investigators. Saxagliptin and cardiovascular outcomes in patients with type 2 diabetes mellitus. N Engl J Med 2013;369:1317-26. doi:10.1056/NEJMoa1307684.

13 Lisa Yanoff MD. Saxagliptin Assessment of Vascular Outcomes Recorded in Patients with Diabetes Mellitus (SAVOR). http://www.fda.gov/ downloads/advisorycommittees/committeesmeetingmaterials/drugs/ endocrinologicandmetabolicdrugsadvisorycommittee/ucm 444144.pd

14 Green JB, Bethel MA, Armstrong PW, et al. TECOS Study Group. Effect of Sitagliptin on Cardiovascular Outcomes in Type 2 Diabetes. N Engl/ Med 2015;373:232-42. doi:10.1056/NEJMoa1501352.

15 White WB, Cannon CP, Heller SR, et al. EXAMINE Investigators. Alogliptin after acute coronary syndrome in patients with type 2 diabetes. N EnglJ Med 2013;369:1327-35. doi:10.1056/NEJMoa1305889.

16 Mogensen UM, Andersson C, Fosbøl EL, et al. Cardiovascular safety of combination therapies with incretin-based drugs and metformin compared with a combination of metformin and sulphonylurea in type 2 diabetes mellitus--a retrospective nationwide study. Diabetes Obes Metab 2014:16:1001-8. doi:10.1111/dom.12314. 
17 Morgan CL, Mukherjee J, Jenkins-Jones S, Holden SE, Currie CJ. Combination therapy with metformin plus sulphonylureas versus metformin plus DPP-4 inhibitors: association with major adverse cardiovascular events and all cause mortality. Diabetes Obes Metab 2014;16:977-83. doi:10.1111/dom.12306.

18 Velez M, Peterson EL, Wells K, et al. Association of antidiabetic medications targeting the glucagon-like peptide 1 pathway and heart failure events in patients with diabetes. J Card Fail 2015;21:2-8. doi:10.1016/j.cardfail.2014.10.012.

19 Wang KL, Liu CJ, Chao TF, et al. Sitagliptin and the risk of hospitalization for heart failure: a population-based study. Int J Cardiol 2014;177:86-90. doi:10.1016/j.ijcard.2014.09.038.

20 Weir DL, McAlister FA, Senthilselvan A, Minhas-Sandhu JK, Eurich DT. Sitagliptin use in patients with diabetes and heart failure: a population-based retrospective cohort study. JACC Heart Fail 2014;2:573-82. doi:10.1016/j.jchf.2014.04.005.

21 Giorda CB, Picariello R, Tartaglino B, et al. Hospitalisation for heart failure and mortality associated with dipeptidyl peptidase 4 (DPP-4) inhibitor use in an unselected population of subjects with type 2 diabetes: a nested case-control study. BMJ Open 2015;5:e007959. doi:10.1136/bmjopen-2015-007959.

22 Moher D, Liberati A, Tetzlaff], Altman DG. PRISMA Group. Preferred reporting items for systematic reviews and meta-analyses: the PRISMA statement. Int J Surg 2010;8:336-41. doi:10.1016/j.ijsu.2010.02.007.

23 ClinicalTrials.gov. Why should I register and submit results? http:// www.clinicaltrials.gov/ct2/manage-recs/background

24 US Food and Drug Administration. Food and Drug Administration Amendments Act (FDAAA) of 2007. US Public Law 110-85 section 801. http://www.gpo.gov/fdsys/pkg/PLAW-110publ85/pdf/ PLAW-110publ85.pdf

25 Akl EA, Sun X, Busse JW, et al. Specific instructions for estimating unclearly reported blinding status in randomized trials were reliable and valid. J Clin Epidemiol 2012;65:262-7. doi:10.1016/j. jclinepi.2011.04.015.

26 Guyatt GH, Busse JW. Modification of Cochrane Tool to assess risk of bias in randomized trials. https://www.evidencepartners.com/ resources/methodological-resources/

27 Higgins JP, Altman DG, Gøtzsche PC, et al. Cochrane Bias Methods Group Cochrane Statistical Methods Group. The Cochrane Collaboration's tool for assessing risk of bias in randomised trials. BMJ 2011;343:d5928. doi:10.1136/bmi.d5928.

28 Higgins JPT, Green S. Cochrane handbook for systematic reviews of interventions. Version 5.1.0. 2011. http://handbook.cochrane.org/

29 Bradburn MJ, Deeks JJ, Berlin JA, Russell Localio A. Much ado about nothing: a comparison of the performance of meta-analytical methods with rare events. Stat Med 2007;26:53-77. doi:10.1002/sim.2528.

30 Friedrich JO, Adhikari NK, Beyene J. Inclusion of zero total event trials in meta-analyses maintains analytic consistency and incorporates all available data. BMCMed Res Methodol 2007;7:5. doi:10.1186/1471-2288-7-5.

31 Sweeting MJ, Sutton AJ, Lambert PC. What to add to nothing? Use and avoidance of continuity corrections in meta-analysis of sparse data. Stat Med 2004;23:1351-75. doi:10.1002/sim.1761

32 Sun X, Briel M, Walter SD, Guyatt GH. Is a subgroup effect believable? Updating criteria to evaluate the credibility of subgroup analyses. $B M$ J 2010;340:c117. doi:10.1136/bmj.c117.

33 Guyatt GH, Oxman AD, Vist GE, et al. GRADE Working Group. GRADE: an emerging consensus on rating quality of evidence and strength of recommendations. BMJ 2008;336:924-6. doi:10.1136/ bmj.39489.470347.AD.

34 Marso SP, Daniels GH, Brown-Frandsen K, et al. LEADER Steering Committee LEADER Trial Investigators. Liraglutide and Cardiovascular Outcomes in Type 2 Diabetes. N Engl J Med 2016;375:311-22. doi:10.1056/NEJMoa1603827.

35 Marso SP, Bain SC, Consoli A, et al. SUSTAIN-6 Investigators. Semaglutide and Cardiovascular Outcomes in Patients with Type 2 Diabetes. N EnglJ Med 2016;375:1834-44. doi:10.1056/NEJMoa1607141.

36 Pfeffer MA, Claggett B, Diaz R, et al. ELIXA Investigators. Lixisenatide in Patients with Type 2 Diabetes and Acute Coronary Syndrome. N Engl J Med 2015;373:2247-57. doi:10.1056/NEJMoa1509225.

37 de Wit HM, Te Groen M, Rovers MM, Tack C). The placebo response of injectable GLP-1 receptor agonists vs. oral DPP-4 inhibitors and SGLT-2 inhibitors: a systematic review and meta-analysis. Br J Clin Pharmacol 2016;82:301-14. doi:10.1111/bcp.12925.

38 Brunton S. GLP-1 receptor agonists VS. DPP-4 inhibitors for type 2 diabetes: is one approach more successful or preferable than the other?Int J Clin Pract 2014;68:557-67. doi:10.1111/ijcp.12361.

39 Boland CL, Degeeter M, Nuzum DS, Tzefos M. Evaluating second-line treatment options for type 2 diabetes: focus on secondary effects of GLP-1 agonists and DPP-4 inhibitors. Ann Pharmacother 2013;47:490505. doi:10.1345/aph.1R444.

40 Zang L, Liu Y, Geng J, et al. Efficacy and safety of liraglutide versus sitagliptin, both in combination with metformin, in Chinese patients with type 2 diabetes: a 26-week, open-label, randomized, active comparator clinical trial. Diabetes Obes Metab 2016;18:803-11. doi:10.1111/dom.12674
41 Van Gaal L, Souhami E, Zhou T, Aronson R. Efficacy and safety of the glucagon-like peptide-1 receptor agonist lixisenatide versus the dipeptidyl peptidase- 4 inhibitor sitagliptin in young ( $<50$ years) obese patients with type 2 diabetes mellitus. J Clin Transl Endocrinol 2014;1:31-7doi:10.1016/j.jcte.2014.03.001.

42 Russell-Jones D, Cuddihy RM, Hanefeld M, et al. DURATION-4 Study Group. Efficacy and safety of exenatide once weekly versus metformin, pioglitazone, and sitagliptin used as monotherapy in drug-naive patients with type 2 diabetes (DURATION-4): a 26-week double-blind study. Diabetes Care 2012;35:252-8. doi:10.2337| dc11-1107.

43 Pratley R, Nauck M, Bailey T, et al. 1860-LIRA-DPP-4 Study Group. One year of liraglutide treatment offers sustained and more effective glycaemic control and weight reduction compared with sitagliptin, both in combination with metformin, in patients with type 2 diabetes: a randomised, parallel-group, open-label trial. Int J Clin Pract 2011;65:397-407. doi:10.1111/j.1742-1241.2011. 02656.x.

44 Nauck M, Weinstock RS, Umpierrez GE, Guerci B, Skrivanek Z, Milicevic Z. Efficacy and safety of dulaglutide versus sitagliptin after 52 weeks in type 2 diabetes in a randomized controlled trial (AWARD-5). Diabetes Care 2014;37:2149-58. doi:10.2337/ dc13-2761.

45 Charbonnel B, Steinberg H, Eymard E, et al. Efficacy and safety over 26 weeks of an oral treatment strategy including sitagliptin compared with an injectable treatment strategy with liraglutide in patients with type 2 diabetes mellitus inadequately controlled on metformin: a randomised clinical trial. Diabetologia 2013;56:1503-11. doi:10.1007/ s00125-013-2905-1.

46 Bergenstal RM, Forti A, Chiasson JL, Woloschak M, Boldrin M, Balena R. Efficacy and safety of taspoglutide versus sitagliptin for type 2 diabetes mellitus (T-emerge 4 trial). Diabetes Ther 2012;3:13. doi:10.1007/s13300-012-0013-8.

47 Bailey TS, Takács R, Tinahones FJ, et al. Efficacy and safety of switching from sitagliptin to liraglutide in subjects with type 2 diabetes (LIRA-SWITCH): a randomized, double-blind, doubledummy, active-controlled 26-week trial. Diabetes Obes Metab 2016;18:1191-8. doi:10.1111/dom.12736.

48 Eli Lilly and Company. United BioSource CorporationTessella Inc. Berry Consultants. A Study of LY2189265 Compared to Sitagliptin in Participants With Type 2 Diabetes Mellitus on Metformin. National Library of Medicine (US), 2000. http://clinicaltrials.gov/show/ NCT00734474

49 GlaxoSmithKline. A Study of the Efficacy and Safety of Albiglutide in Subjects With Type 2 Diabetes With Renal Impairment. National Library of Medicine (US), 2000. http://clinicaltrials.gov/show/ NCT01098539

50 GlaxoSmithKline. Efficacy and Safety of Albiglutide in Treatment of Type 2 Diabetes. National Library of Medicine (US), 2000. http:// clinicaltrials.gov/show/NCT00838903

51 Monami M, Cremasco F, Lamanna C, et al. Glucagon-like peptide-1 receptor agonists and cardiovascular events: a meta-analysis of randomized clinical trials. Exp Diabetes Res 2011;2011:215764. doi:10.1155/2011/215764

52 Monami M, Dicembrini I, Nardini C, Fiordelli I, Mannucci E. Effects of glucagon-like peptide-1 receptor agonists on cardiovascular risk: a meta-analysis of randomized clinical trials. Diabetes Obes Metab 2014:16:38-47. doi:10.1111/dom.12175.

53 Ding S, Du YP, Lin N, et al. Effect of glucagon-like peptide-1 on major cardiovascular outcomes in patients with type 2 diabetes mellitus: A meta-analysis of randomized controlled trials. Int / Cardiol 2016:222:957-62. doi:10.1016/j.ijcard.2016.07.199.

54 Monami M, lacomelli I, Marchionni N, Mannucci E. Dipeptydil peptidase- 4 inhibitors in type 2 diabetes: a meta-analysis of randomized clinical trials. Nutr Metab Cardiovasc Dis 2010;20:224 35. doi:10.1016/j.numecd.2009.03.015.

55 Savarese G, Perrone-Filardi P, D’Amore C, et al. Cardiovascular effects of dipeptidyl peptidase-4 inhibitors in diabetic patients: A meta-analysis. Int J Cardiol 2015;181:239-44. doi:10.1016/j. ijcard.2014.12.017.

56 Wu S, Hopper I, Skiba M, Krum H. Dipeptidyl peptidase-4 inhibitors and cardiovascular outcomes: meta-analysis of randomized clinical trials with 55,141 participants. Cardiovasc Ther 2014;32:147-58. doi:10.1111/1755-5922.12075

57 Savarese G, D’Amore C, Federici M, et al. Effects of Dipeptidyl Peptidase 4 Inhibitors and Sodium-Glucose Linked coTransporter-2 Inhibitors on cardiovascular events in patients with type 2 diabetes mellitus: A meta-analysis. Int J Cardiol 2016;220:595-601. doi:10.1016/j.ijcard.2016.06.208.

Appendix 1: Search strategies

Appendix 2: Supplementary tables A-D Appendix 3: Supplementary funnel plots 